\title{
AVALIAÇÃO DE EMERGÊNCIA DO FAVÃO (Parkia multijuga) PARA REABILITAÇÃO EM ÁREAS IMPACTADAS POR EXTRAÇÃO DE ARGILA
}

\author{
Jayane Santos Nunes ${ }^{1}$; Clarissa Mendes Knoechelmann²; Andréa Hentz de \\ Mello $^{3}$; Raimundo Nonato do Espírito Santos ${ }^{4}$; Ana Valéria dos Reis Pinheiro ${ }^{4}$ \\ ${ }^{1}$ Discente do curso de Agronomia, Faculdade de Ciências Agrárias de Marabá (FCAM), Universidade \\ Federal do Pará (UFPA), bolsista do SINDCERV, jayzinhanunes@ hotmail.com \\ 2 Professora Assistente I, FCAM, UFPA, clarrissa@ufpa.br \\ ${ }^{3}$ Professora Adjunta I, FCAM, UFPA, andreahentz@ufpa.com \\ ${ }^{4}$ Professor(a) Adjunto, Faculdade de Geologia, UFPA
}

\begin{abstract}
RESUMO: A recuperação de áreas degradadas é uma prática de extrema importância para a diversidade do ecossistema perturbado. A maioria das áreas em que são realizadas atividades de extração de argila em Marabá-PA encontra-se degradadas, devido à retirada da vegetação natural, o que facilita o processo de erosão. As leguminosas arbóreas são bastante eficientes em recuperação de áreas degradadas. Este trabalho analisa a taxa de emergência do favão (Parkia multijuga) para recuperação de áreas degradas por extração de argila na cidade de Marabá- Pará. O estudo foi conduzido na Universidade Federal do Pará, campus de Marabá em casa de vegetação, onde as sementes do favão passaram pelo processo de quebra de dormência, que consistiu em escarificação mecânica em superfície cimentada áspera, e sua semeadura foi realizada, em saco de polietileno com capacidade de $1 \mathrm{~kg}$ de substrato, na proporção $50 \%$ de solo, oriundo da área a ser reabilitada e $50 \%$ de esterco bovino. Foram semeadas 90 sementes de favão, onde em cada saco de polietileno foi semeado uma semente, que foram assistidas por 90 dias e regadas três vezes ao dia até estas estarem aptas a serem levadas ao campo. A emergência do favão foi de $100 \%$ baseando-se no cálculo de regra de três simples, porém 32 mudas morreram por ataque de fungos. O experimento mostrou que a taxa de emergência do favão foi alta e rápida em condições de casa de vegetação.
\end{abstract}

PALAVRAS-CHAVE: Casa de vegetação, degradação, leguminosa arbórea.

\section{EVALUACIÓN DE EMERGENCIA DE (Parkia multijuga) PARA LA REHABILITACIÓN EN ZONAS AFECTADAS POR LA EXTRACCIÓN DE ARGILA}

RESUMEN: La recuperación de áreas degradadas es una práctica de extrema importancia para la diversidad de los ecosistemas perturbados. La mayoría de las áreas en que las actividades se llevan a cabo la extracción de arcilla en Marabá-PA son degradadas debido a eliminación de la vegetación natural, lo que facilita el proceso de erosión. Los árboles de leguminosas son muy eficientes en la recuperación de áreas degradadas. Este estudio examina la tasa de aparición de Parkia multijuga para la recuperación de áreas degradadas por la extracción de arcilla en la ciudad de Marabá, Pará El estudio se llevó a cabo en el invernadero de la Universidad Federal de Pará, Campus de Marabá, donde las semillas habían pasado por el proceso de rompimiento de la dormencia, que consistió en la escarificación mecánica sobre la superficie de cemento en bruto, y su siembra fue en bolsas de polietileno con una capacidad de $1 \mathrm{~kg}$ de sustrato, en el suelo porcentaje del 50\%, derivado de la zona que se rehabilitación y el 50\% de las deyecciones ganaderas. Se sembraron 90 semillas, donde en cada bolsa de polietileno se sembraron una semilla, que fueron asistidos por 90 días y regadas tres veces al día hasta que son capaces de ser llevados al campo. La aparición de P. multijuga fue de $100 \%$ basado en el cálculo de regla de tres simple, pero el 32 plántulas murieron por ataque de 
hongos. El experimento mostró que la tasa de aparición de haba era alto y rápido en las condiciónes de efecto invernadero.

PALABRAS CLAVE: Efecto invernadero, degradación, árbol leguminosa.

\section{INTRODUÇÃO}

A degradação de ambientes naturais é visto como um dos grandes problemas na atualidade, este ocorre devido à caminhada predatória para o desenvolvimento, facilitando em grandes perdas da diversidade natural do meio (MANTOVONI et al., 1998).

Recuperação de áreas degradadas torna-se uma alternativa importantíssima para o meio ambiente e social, pois busca com estudos e ações amenizar impactos ocasionados devido ao mau uso dos recursos naturais (SILVA, 2007).

A maioria das áreas em que são realizadas atividades de extração de argila em Marabá-PA encontra-se degradadas, devido à retirada da vegetação natural, o que facilita o processo de erosão. O solo da área apresentase erodido, com considerável quantidade de rejeito, prejudicando também a microbiota do solo que tem papel fundamental na ciclagem de nutrientes e no mananciais de água, como as margens do rio Itacaiúnas.

As leguminosas lenhosas e herbáceas são muito eficiente em recuperação de áreas degradadas, pois fixam nitrogênio da atmosfera e produzem grande quantidade de biomassa e conseqüentemente alta ciclagem de nutriente. O favão (Parkia multijuga Beth) faz parte das família leguminosas e é comum sua ocorrência na região Amazônica, em floresta de terra firme e várzeas altas em solos argilosos. Sua floração ocorre geralmente durante os meses de agosto e outubro e a maturação dos frutos no período de novembro a dezembro (LORENZI, 2000).

Diante da necessidade da recuperação dos ecossistemas impactados, este trabalho analisa a taxa de emergência do favão $(P$. multijuga) para recuperação de áreas degradas por extração de argila na cidade de MarabáPará.

\section{MATERIAL E MÉTODOS}

O estudo foi conduzido na Universidade Federal do Pará, campus de Marabá em casa de vegetação. As sementes da leguminosa arbórea usada no experimento são procedentes do banco de germoplasma da Eletronorte de Tucuruí do estado do Pará.

As sementes do favão passaram pelo processo de quebra de dormência, antes da semeadura, que consistiu em escarificação mecânica em superfície cimentada áspera até aparecer à cor clara dos cotilédones. Sua semeadura foi realizada dia 05 de julho de 2010, em saco de polietileno com capacidade de $1 \mathrm{~kg}$ de substrato, na proporção $50 \%$ de 
solo, oriundo da área a ser reabilitada e 50\% de esterco bovino.

Foram semeadas 90 sementes de favão mantidas em casa de vegetação. Em cada saco de polietileno foi semeado com uma semente da espécie. Estas foram regadas três vezes ao dia, durante três meses, até estarem aptas a serem levadas ao campo.

\section{RESULTADOS E DISSCUSSÃO}

A primeira emergência do favão ocorreu no dia 12 de julho de 2010, isto é, após cinco dias de semeada. Segundo Lorenzi, (2000) a taxa de germinação do favão é alta quando mantido em ambiente semi-sombreado e sua emergência ocorre entre 20 a 40 dias.

A taxa de emergência da espécie semeada foi de $100 \%$, onde para obter este resultado foi usado regra de três simples usando o valor de plântulas emergidas com a quantidade de plantas semeadas. Estes dados corroboram com Carmargo et al. (2002) que em testes de semeadura direta e em condição de área sem vegetação a espécie apresentou alta sobrevivência (76 - $92 \%$ ), porém a taxa de germinação foi relativamente baixa $(<50$ \%). Uma germinação mais rápida $\mathrm{e}$ homogênea é vantajosa para qualquer produção de mudas em viveiros, pois facilita um melhor controle das atividades subsequientes até ao destino final da muda (OLIVEIRA et al, 2003).
Logo depois a emergência, a maioria das plântulas de favão foram atacadas por fungos levando 32 mudas a morte. Para Neergard (1997) os fungos são responsáveis por grande parte das perdas de sementes germinadas e de plântulas de espécies florestais na prática de produção de mudas em viveiros.

A temperatura e umidade altas facilitaram a propagação do fungo na plântula do favão. Fatores do ambiente como temperatura e umidade são os que mais influenciam no desenvolvimento de patógenos nas plantas, influenciando no número e em suas atividades (MICHEREFF, 1998). Segundo a classificação de Almeida (2006) o clima regional é do tipo Awi tropical chuvoso de savana com temperatura média anual de $26,35^{\circ} \mathrm{C}$, máxima de $31,0^{\circ} \mathrm{C}$ e mínima de $23,0^{\circ} \mathrm{C}$, caracterizada por um período menos chuvoso entre os meses de maio a outubro e um período mais chuvoso entre os meses de novembro a abril. A produção de mudas do favão é uma alternativa eficiente em casa de vegetação, para recuperação de áreas degradas, pois possui alta emergência de plântulas.

\section{CONCLUSÃO}

$\mathrm{O}$ experimento mostrou que a taxa de emergência do favão foi alta e rápida em condições de casa de vegetação. 


\section{REFERÊNCIAS}

CAMARGO, J. L. C.; FERRAZ, I. D. K.; IMAKAWA, A. M. Rehabilitation of Degraded Areas of Central Amazonia Using Direct Sowing of Forest Tree Seeds. Restoration Ecology, v. 10, n. 4, p. 636-644, 2002.

FRANCO, A. A.; CAMPELlO, E. F. F. C.; SILVA, E. M. R.; FARIA, S. M. Revegetação de Solos Degradados. Seropédica: Embrapa-CNPBS, 1992. 11p. (Embrapa-CNPBS. Comunicado técnico, 9).

KOEPPEN, W. Climatologia Tradicional. Traduzido para o Espanhol por Pedro Henchiehs Pérez, 1948.

LORENZZI, H. Árvores brasileiras: Manual de identifição e cultivo de plantas arbóreas do Brasil. Nova Odessa: Instituto Plantarum de Estudos da Flora LTDA, 2008.

MICHEREFF, S. J. Queima das folhas do inhame: quantificação, levantamento da intensidade e dinâmica espaço temporal. Viçosa. 1998. 92 f. Tese (Doutorado em fitopatologia) - Universidade Federal de Viçosa. Departamento de fitopatologia.

NEERGARD, P. Seed. Pathology. London: MacMillian Press, 1997. 839 p.

OLIVEIRA, L. M., DAVIDE, A. C., CARVALHO, M. L. M. Avaliação de métodos para quebra de dormência e para desinfestação de sementes de canafístula (Peltophorum dubium (Sprengel)) Taubert. Revista Árvore, v. 27, n.5, p. 597-603, 2003.

SILVA, J. C. S. Desenvolvimento inicial de espécies lenhosas nativas e de uso múltiplo na recuperação de áreas degradadas de cerrado sentido restrito - DF. Brasília. 2007. 120 f. Dissertação (Mestrado em Engenharia Florestal) - Universidade de Brasília, Faculdade de Tecnologia, Departamento de Engenharia Florestal.

\section{AGRADECIMENTOS}

O presente trabalho foi realizado com o apoio do SINDCERV Marabá - PA. 